\title{
Technology Development of Glycosyl Resins for Wood Composites
}

\author{
Wei-Xing Gan ${ }^{1}$, Hai-Bing Yang ${ }^{1}$, Yi-Fu Zhang ${ }^{1}$ and Sheldon Q Shi ${ }^{1,2 *}$ \\ ${ }^{1}$ College of Forestry, Guangxi University, China \\ ${ }^{2}$ Mechanical and Energy Engineering Department, University of North Texas, USA
}

Submission: July 31, 2017; Published: September 15, 2017

*Corresponding author: Sheldon Q Shi, College of Forestry, Guangxi University, China and Mechanical and Energy Engineering Department, University of North Texas, 3940 N Elm, Suite F101, USA, Tel: 762077102; Email: Sheldon.shi@unt.edu

\begin{abstract}
The synthesis methods for renewable and eco-friendly glycosyl adhesives were reviewed. The low molecular weight carbohydrate-based adhesives and the carbohydrate modified urea-formaldehyde resin, melamine-formaldehyde resin, phenol-formaldehyde resin and polyurethane resin were discussed. The paper provides an understanding of glycosyl adhesive synthesis, and its utilization in modifying different formaldehyde based adhesives. Hydroxyl and furfural reactions have been the main synthesis methods for the glycosyl adhesive and the glycosyl modified formaldehyde-based adhesives. The current adhesive synthesis methods have been highly dependent on the specific conditions, while most of the synthesis processes are not suitable for scaling up. The future research should focus on identifying an effective curing agent in order to reduce the curing temperature, pressure and the reaction time, in order for the commercialization of the glycosyl based adhesives.
\end{abstract}

Keywords: Glycosyl adhesive; Carbohydrate; Wood composites

\section{Introduction}

Currently, most adhesives used in wood-based composites are formaldehyde-based, such as phenol formaldehyde (PF) resin, urea formaldehyde (UF) resin, melamine urea formaldehyde (MUF) resin, etc., and the raw materials of these adhesives are processed from petroleum and natural gas, which are nonrenewable [1]. Formaldehyde is considered as a toxic and harmful chemical stimulating skin, eye and mucosa, which obligate to inducing some diseases (EPA 2009). It has a deadly threat on human health. In 2007, the California Air Resources Board (CARB) approved regulations to set a limitation on formaldehyde emissions for the wood-based composites, such as hardwood plywood, medium-density fiberboard (MDF), and particleboard. The U.S. Department of Housing and Urban Development (HUD) also set a standard to limit the formaldehyde emissions from wood products. In 2010, the US Congress enacted a legislation mandating a national emission standard for the composite wood products. Many other countries, such as European Union, China and Japan, have implemented regulations to limit the formaldehyde emission from wood and wood based products to minimize indoor air pollution. Pressure has been on wood adhesive industry to produce eco-friendly products. In addition, due to the limitation of petroleum resources, unstable fossil fuel prices, and environmental concerns, there is a more demand on the development of sustainable and environmentfriendly adhesives [2-4].

Carbohydrates (glucose, fructose, and sucrose, etc) are renewable and biodegradable materials, which can be processed into environmentally friendly polymeric products $[5,6]$. The low cost and adjustable structure make the carbohydrates attractive to be used as a substitute for synthetic polymers. Carbohydrates are rich in hydroxyl groups (Figure 1), which are ideal for the bonding with lignocellulose materials [6]. However, a certain modification treatment may be necessary to make it more suitable for the cross linking reaction through degradation or blending [7]. The glycosyl adhesives discussed herein refer to a series of modified resins from low molecular carbohydrates with the traditional adhesives, such as amino resins [8] and polyurethane [9]. In the past years, many researchers put in effort to study the sugar based resins for wood-based composites $[10,11]$. The objective of this paper is to summarize the technology development of glycosyl adhesives and their applications in wood composites, and to identify the issues and the future directions for the glycosyl resin developments. 


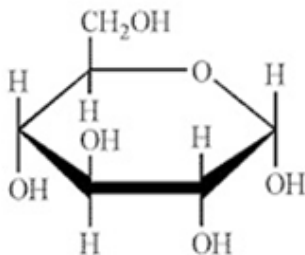

Glucose

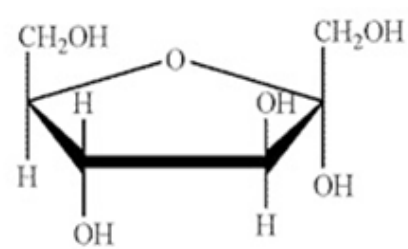

Fructose

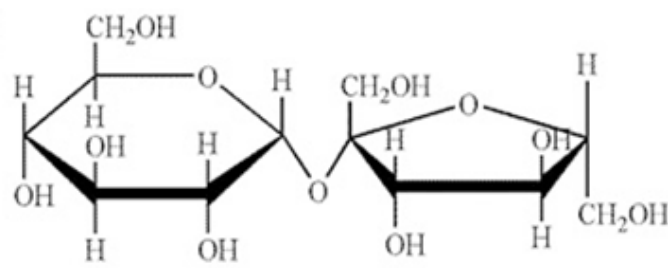

Sucrose

Figure 1: The structure of monosaccharide.

\section{Glycosyl Adhesive Synthesis}

Viswanathan [12] developed a thermosetting adhesive prepared by heating up an aqueous sugar or starch solution in the presence of an inorganic acid or an ammonium salt using a metal ion catalyst, and a partially polymerized resin was obtained. A simple carbohydrate was dehydrated to an active monomeric species of 5-hydroxymethyl-2-furfuraldehyde (HMF) in a strong acid. The HMF reacts with condensing agents, urea and phenol, in the presence of a catalyst. The results from the follow-up work [12] indicated that the polymer formation could be induced not only through the HMF formation, but also through other pathways for the polymerization reactions. Thus, a complex network with different molecules could be formed, in which the HMF was presented only as a small fraction of the whole polymer chain. Based on a qualitative test to determine the free sugars, intact sugar molecules were found, and it was believed that the hydroxyl groups of the carbohydrates could be cross-linked [4], so that a network with a higher molecular weight could be obtained. The cross links would take place at the secondary hydroxyls of carbohydrate $[12,13]$.

Two main reactions for the synthesis of lactose based resin can be described in Figure 2:

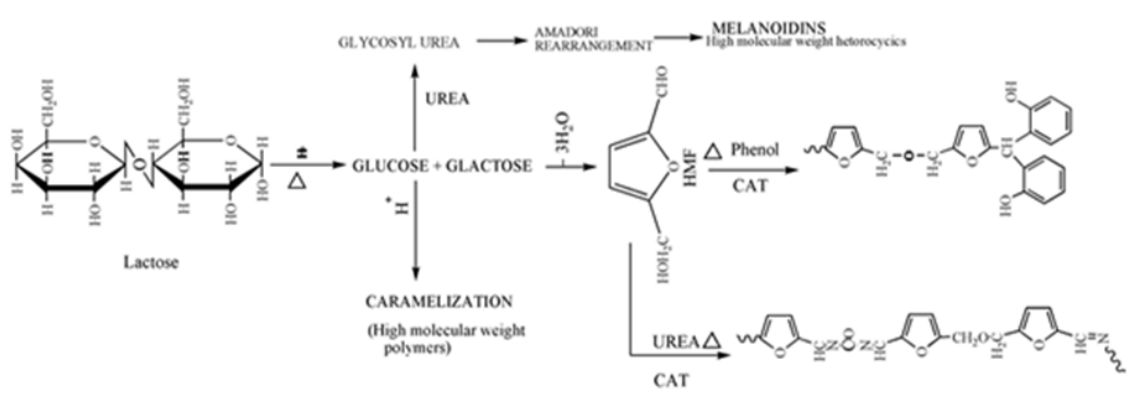

Figure 2: Synthesis of lactose based resins.

a. Furfural reaction, which is based on the HMF prepared from the fructose.

b. Reactions between the hydroxyl groups of carbohydrate and the active groups of monomer, such as amino from urea or melamine, hydroxyls from the methylation, and orthopara position of the phenolic compound.
The HMF is a chemical intermediate, which is used to dehydrate the lignocellulose. Carbohydrate, such as fructose, can be dehydrated to HMF with various liquid/solid acids in different solvents. For the glucose, it would first be isomerized into fructose. The fructose is further dehydrated to HMF with a solid acid catalyst [14]. The chemical reactions are described in Figure 3 \& 4 .

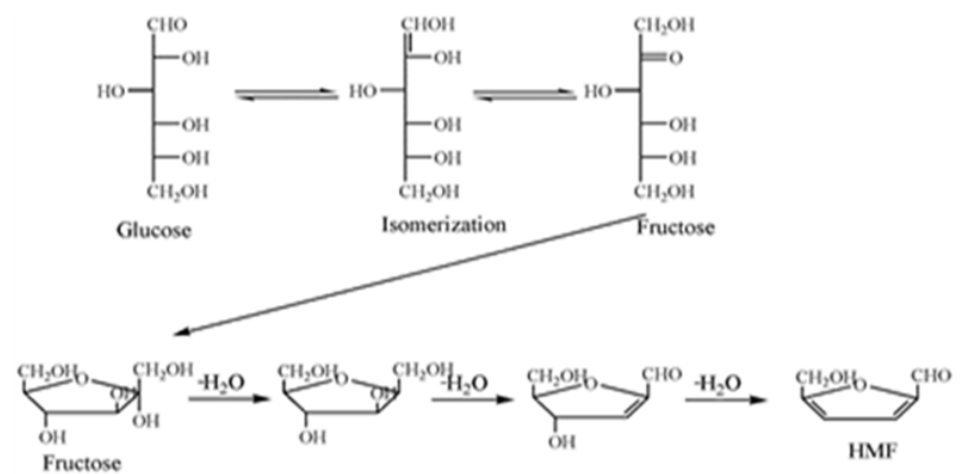

Figure 3: Furfural reaction for the synthesis of HMF. 


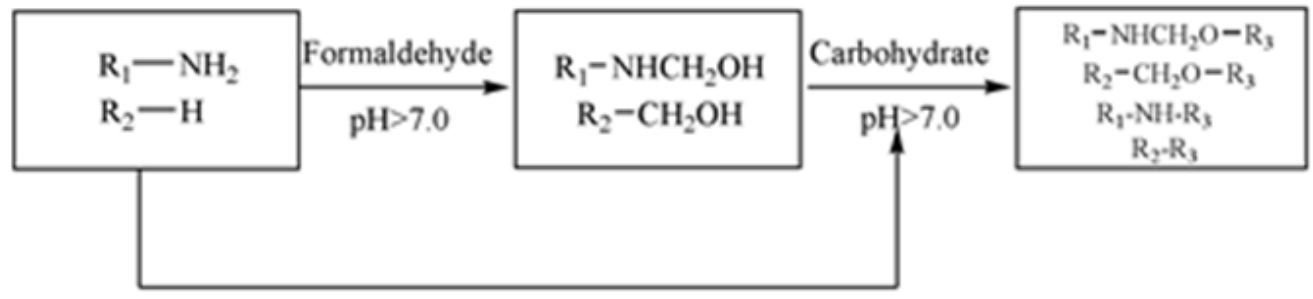

\section{$R_{1}=$ UREA, MELAMINE $\mathrm{R}_{2}=$ PHENOL \\ $\mathrm{R}_{3}=$ CARBOHYDRATE}

Figure 4: Synthesis of HMF

The glycosyl adhesive synthesized through the furfural reaction does not require using formaldehyde. However, the process may not be practical as the required adhesive curing conditions are difficult to achieve. For example, using a curing agent like phthalic anhydride, the curing time for the glycosyl adhesive from the furfural reaction could be as long as 90 minutes, which may not be practical [15]. The reaction through the hydroxyl groups has usually been used to modify the wood adhesives, such as amino resin and phenol-formaldehyde resin, to improve the performance [16]. Costa et al. [8] prepared low molecular weight intact carbohydrate, such as glucose, fructose and sucrose, from biomass (such as starch), which can be served as cross-linking agents for amino resins and PU resins.

\section{Glycosyl Modified Urea-Formaldehyde (UF) Resin}

Urea has a carbamide structure, which can be reacted with formaldehyde, to form two intermediate products: monomethylol-urea and di-methylol-urea [17]. These two products will build a condensation to form UF resin. UF resin has been the main binding agent for particleboard and medium density fiberboard [18], with the advantages of low cost, high bonding strength and fast curing $[19,20]$. Two reactions, hydroxyl and furfural, can be considered for the glycosyl modification of UF resin.

\section{Reaction through hydroxyl groups}

The approach is simple and cost effective to obtain carbohydrate with a low molecular weight. A glycosyl modified UF adhesive [20,21] was prepared using the cassava starch hydrolysate. The wood composites bonded with the glycosyl modified UF resin showed a bonding strength of $0.8 \mathrm{MPa}$ with a free formaldehyde emission of $1.2 \mathrm{mg} / \mathrm{L}$. An optimized formulation was suggested as, viscosity of hydrolysate: $40.0 \mathrm{~s}$ 45.0s (Tu-4 Cup, $30{ }^{\circ} \mathrm{C}$ ); mole ratio (formaldehyde to urea): 1.3; and melamine content: $3.6 \%$.

\section{Furfural reaction}

The formaldehyde emission for the UF bonded wood composites has been a concern in terms of the indoor air quality [22]. In order to reduce the formaldehyde emission, researcher used a lower mole ratio (formaldehyde to urea), such as 1.05
[23] or incorporated a small amount of melamine into the UF resin to form polycompound [24]. Replacing formaldehyde with carbohydrate could be an effective way to formulate eco-friendly and formaldehyde-free adhesives.

Song [25] converted sucrose to HMF through decomposing reaction using metal catalyst, in accordance with the principle of furfural reaction in an acidic condition as the first step. The network was formed through a chemical reaction between HMF and a cross linker, biuret. An optimum reaction condition was suggested as: mole ratio (sucrose to biuret), 10:1; $\mathrm{pH}$ value, 1.0; catalyst amount, $0.4 \mathrm{~g}$; and reaction temperature, $95{ }^{\circ} \mathrm{C}$. The results from Fourier Transform Infrared Spectroscopy (FTIR) showed that a new carbonyl compound was produced, which had confirmed the speculated mechanism of Viswansthan [12] at a wave number of $1,718.86 \mathrm{~cm}-1$. Glucose [26] and fructose [27] were dehydrated to the HMF in accordance with the mechanism of furfural prior to reacting with biuret or urea, so that the resin was synthesized in an acidic condition with a $\mathrm{pH}$ value of 1.0 and a temperature of $95{ }^{\circ} \mathrm{C}$. The curing reaction of the adhesive was conducted in a condition at a catalyst content of $8 \%$ (wt \%) and curing time of $1.5 \mathrm{~h}$.

\section{Glycosyl Modified Melamine-Formaldehyde Resin}

Melamine formaldehyde (MF) resin is synthesized through a condensation polymerization between methylated melamine and formaldehyde. MF is a thermosetting resin used as adhesives, coating agents, and modifiers of other materials [28]. In the wood composites industry, MF resin has mainly been used for impregnated papers [29] with enhanced hardness and toughness. Melamine is a heterocyclic compound with a triazine network structure, which has a good water resistance property [30]. Therefore, melamine has been considered a good resin used for the modification of other adhesives, such as UF resin [31], and polyvinyl acetate (PVA) resin [32] for the improvement of the water resistance of the composite products. Incorporation of carbohydrate may reduce the melamine amount for the Hydroxyl number, volatile organic compound (VOC) emission from the composites could be reduced. The glycosyl modification of MF resin could also be involved in two reactions, hydroxyl and furfural. 


\section{Reaction through hydroxyl group}

Based on the structure of hydroxyl groups of sugar, it would be possible to induce a carbohydrate ring into the network structure of MF resin [33]. Gan \& Wu [34] synthetized a sucrosemelamine-formaldehyde (SMF) resin using sucrose, melamine and formaldehyde in an alkaline condition, and an optimum synthesis condition was obtained as: mole ratio (sucrose to melamine), 0.7:1; mole ratio (formaldehyde to melamine), 2.7:1; the content of cross linking, $0.33 \%$ (wt $\%$ ). The bonding strength of SMF bonded plywood was obtained as $0.7 \mathrm{MPa}$. The pot life of the synthesized SMF resin was 7 days longer compared to the control sample of MF resin. [35] recently developed a synthesis method for maltose- melamine- formaldehyde adhesive (MMF) through introducing the maltose into the melamine based resin. The pot life of synthesized MMF was much improved compared to the traditional MF resin $[36,37]$. This new formulation can be a better substitute of the MF resin used in wood composites.

\section{Furfural reaction}

Chen \& Zhang [38] reported a synthesis method of a formaldehyde- free melamine- glucose adhesive (MG), which behaves similar to the UF adhesive. MG was obtained through condensation polymerization process in a chemical reaction between melamine and glucose with a promoter of NH4NO3 and $\mathrm{HCl}$ at a high temperature for a few hours. Compared to the UF resin, MG is lower in cost and has less formaldehyde emission. Gui et al. [39] prepared a lactose-melamine resin using the lactose to replace formaldehyde in an acidic condition. Optimum synthesis parameters for the resin were found as: mole ratio (lactose to melamine), 6:1; catalyst content, $0.98 \%$ (wt\%); reaction temperature, $199.8^{\circ} \mathrm{C}$. The experimental results showed that the bonding strength reached $30.89 \mathrm{MPa}$, which was similar to that of UF resins.

\section{Glycosyl Modified PF Resin}

PF resin has advantages in bonding strength, and resistances to water, chemical agents and weather. The PF resin was synthesized based on a co-condensation process between phenol and formaldehyde in an alkaline condition. PF resin has been used for many decades as exterior grade wood composite products [40]. It was reported that the carbohydrate could be used to replace the formaldehyde partially or totally in the PF formulation [41]. The formaldehyde emission of the composite product bonded by the glycosyl modified PF can be significantly reduced.

The phenolic structure with binary hydroxyl has a better reactivity than phenol, as it has more reaction sites to be cross linked easily with aldehyde and ketone. According to the furfural mechanism, sucrose, lactose and glucose and other carbohydrate with low molecular weight can be dehydrated into HMF at high temperatures. Polymerization reaction happens between the phenolic structure and the HMF. It was reported that the sucrose-catechol resin could be synthesized using sucrose and hydroquinone [42]. A response surface analysis with 4 factors and 5 levels was used to obtain the optimum reaction parameters as: reaction temperature, $92.1{ }^{\circ} \mathrm{C}$; sucrose to catechol mole ratio, 1.65:1, and catalyst content, $9 \%$ (wt\%). Chen et al. [43] prepared a thermosetting resin using resorcinol and lactose in an acidic condition. Optimum synthesis parameters were obtained as: mole ratio (lactose to resorcinol), 4.5:1; CuSO4 content, 2.1g; NH4NO3 content, $13 \mathrm{~g}$; $\mathrm{HCl}$ content, $3 \mathrm{~mL}$; and curing temperature, $100{ }^{\circ} \mathrm{C}$. It was reported that fructose-pyrocatechol resin [44] and fructose-paracresol resin adhesive [45] have been prepared.

\section{Glycosyl Modified Polyurethane (PU) Resin}

PU resin is a class of polymers with high performance and versatile $[46,47]$. PU resin can be formulated with different hydroxyl numbers. Desai et al. [48] obtained a polyurethane adhesive system using bio-based polyol prepared from the glycosylation product of starch and plantation oils through a transesterification reaction. In this research, the glycol glycoside was firstly prepared to obtain polyol through a reaction between starch and ethylene glycol in an acidic condition. The alcoholysis of oil with glycol glycoside was conducted under a high temperature and the presence of lithium hydroxide. Then the toluene diisocyanate (TDI)-based product was mixed, so that the PU resin was synthesized. Compared to many other commercial wood adhesives, the synthesized PU adhesive was found to have superior bonding property, and an optimum ratio of $\mathrm{NCO} / \mathrm{OH}$ was found to be 1.3:1.

\section{Conclusion}

Much research work has been conducted on the glycosyl resins in the applications for bonding lignocellulosic materials. Hydroxyl and furfural reactions have been the main synthesis methods for the glycosyl adhesive and the glycosyl modified formaldehyde-based adhesives. The current resin synthesis methods have been highly dependent on the specific conditions, while most of the current synthesis processes may not be practical. The low molecular weight carbohydrate has been used to modify urea-formaldehyde resin, melamine-formaldehyde resin, phenol-formaldehyde resin and polyurethane resin. It is important to understand the synthesis mechanism for the glycosyl resin, and to identify an effective curing agent in order to lower the curing temperature, reduce the pressure and decrease the reaction time.

\section{Acknowledgement}

The authors would like to thank "Chinese National Science and Technology Support Program (2015BAD14B03)" and "Natural Science Foundation of China (31360158)" for the financial support.

\section{References}

1. Imam SH, Gordon SH, Mao L, Chen L (2001) Environmentally friendly wood adhesive from a renewable plant polymer: characteristics and optimization polymer degradation and stability. Scientific research an academic publishers 73: 529-533. 
2. Huysveld S, Meester SD, Iinden VV (2015) Resources, Conservation and Recycling. 102: 113-127.

3. Panchal T, Chauhan D, Thomas M (2015) Industrial Crops and Products. 63: 48-52.

4. Ciannamea EM, Stefani PM, Ruseckaite RA (2010) Bioresource Technology. 101: 818-825.

5. Matjaž K, Sergej M, NatašaC` UK (2010) Bioresource Technology. 101: 1361-1368.

6. Wan Y, Luo H, He F (2009) Composites Science and Technology. 69: 1212-1217.

7. Ramli NAS, Amin NAS (2015) Journal of Molecular Catalysis A: Chemical. 407: 113-121.

8. Costa NA, Pereira J, Ferra J (2013) Journal of Adhesion Science and Technology. 27(7): 763-774

9. Desai SD, Patel JV, Sinha VK (2003) Polyurethane adhesive system from biomaterial-based polyol for bonding wood. International Journal of Adhesion \& Adhesives 23: 393-399.

10. Xiao J, Dang Y, Peng M (2009) Applied Science and Technology. 136: 5-7.

11. Guo J, Zhang X, Wang Y (2011) Applied Science and Technology. 38: 67-70.

12. Viswanathan T, Richardson $\mathrm{T}$ (1984) Industrial and engineering chemistry product research and development. ACS Publication 23(3): 323-511.

13. Viswanathan $T$, Gllton $T$ (1986) Industrial and engineering chemistry product research and development. ACS Publication 25(1): 313-315.

14. Huang H, Denard CA, Alamillo R (2014) Tandem catalytic conversion of glucose to 5-hydroxymethylfurfural with an immobilized enzyme and a solid acid. ACS Catalysis 4(7): 2165-2168.

15. Long Y, Yang K, Yu X (2008) Materials Research and Application. 2: 400-404.

16. Kaboorani A, Riedl B (2011) International Journal of Adhesion \& Adhesives. 31: 605-611.

17. Wohnsiedler HP (1952) Industrial and Engineering Chemistry. 41: 2679-2986.

18. Liu Y, Zhu X (2014) Construction and Building Materials. 66: 132-137.

19. Marra A, Nostrand V (1992) Reinhold, New York, USA, p. 80.

20. Schultz J, Nardin M (1994) In Handbook of Adhesive Technology. In: Pizzi A, Mittal KL (Eds.), Marcel Dekker: New York, USA, p. 19.

21. Pan L, Gan W, Mo D (2014) Journal of Guilin University of Technology. 34: $147-150$

22. Gan W, Pan L, Yang H (2014) China, CN103665288A.
23. Cruz G (2007) Grilling Time. Internet edition.

24. Mao A, Hassan EB, Kim MG (2013) Bio Resources. 8: 2470-2486.

25. Siimer K, Kaljuvee $T$ (2010) Journal of Thermal Analysis and Calorimetry. Physical chemistry 99: 755-762.

26. Song W, Wang J, Guo Y (2010) Chemistry and Adhesion 32: 75-77.

27. Chen S, Zhang L, Xu X (2007) Chemistry and Adhesion 29: 10-12.

28. Chen S, Wang X, Zhao Q (2008) Chemistry and Adhesion 30: 27-30.

29. Peter F, Regina H (2001) USA, 19962273.

30. Liu Y, Zhu X (2014) Construction and Building Materials 66: 132-137.

31. Zhou Y, Yan Y, Du Y (2013) Sensors and Actuators B: Chemical 188: 502-512.

32. Siimer K, Kaljuvee $T$ (2010) Journal of Thermal Analysis and Calorimetry 99: 755-762.

33. Kaboorani A, Riedl B (2011) International Journal of Adhesion \& Adhesives 31: 605-611.

34. Gan W, Wu N, Yan Y (2011) China Forest Products Industry 38: 18-25.

35. Gan W, Wu N (2011) China, CN102115652A.

36. Gan W, Yang H, Pan L (2014) China, CN103666350A.

37. Yang H, Gan W, Pan L (2015) China Forest Products Industry 42: 2933.

38. (2009) An Introduction to Indoor Air Quality-Formaldehyde, Environmental Protection Agency.

39. Chen S, Zhang L (2005) Science in China Ser. B Chemistry, 48: 29-32.

40. Gui X, Zhang X, Gao Y (2013) New Chemical Materials 41: 41-43.

41. Zhao C, Pizzi A, Garnier S (1999) Journal of Applied Polymer Science 74: 359-378.

42. Gao Y (2008) Adesion in China, 29: 31-33.

43. Guo J, Zhang X, Wang Y (2011) Applied Science and Technology 38: 67-70.

44. Chen S, Liu Z, Xu X (2006) China Adhesives 15: 25-27.

45. Zhang X, Guo J, Chen S (2010) International water-based adhesive technology seminar, shanghai, China.

46. Wu W, Gao Y, Chen S (2008) Chemistry and Adhesion 30: 19-20.

47. Oertel G (1985) Hanser Publishers, New York, USA.

48. Jia D, Pang Y, Liang X (1994) PolymSci Part B: Polym Phys 32: 817823.

49. Desai DS, Patel JV, Sinha VK (2003) International Journal of Adhesion \& Adhesives, pp. 393-399. 
This work is licensed under Creative Commons Attribution 4.0 Licens

DOI: 10.19080/MABB.2017.02.555577

\section{Your next submission with Juniper Publishers will reach you the below assets}

- Quality Editorial service

- Swift Peer Review

- Reprints availability

- E-prints Service

- Manuscript Podcast for convenient understanding

- Global attainment for your research

- Manuscript accessibility in different formats ( Pdf, E-pub, Full Text, Audio)

- Unceasing customer service

Track the below URL for one-step submission https://juniperpublishers.com/online-submission.php 